\title{
Cold reacting anti-M causing delayed hemolytic disease of the newborn
}

\author{
Philip Crispin $\mathbb{1}^{1},{ }^{1,2,3}$ Kelly Sliwinski, ${ }^{1}$ Caroline Wilson, ${ }^{2}$ Samantha Lennard, ${ }^{1}$ Marianne DeSouza, ${ }^{1}$ and \\ Farah Sethna ${ }^{4}$
}

BACKGROUND: Hemolytic disease of the fetus and newborn (HDFN) is due to passively transferred maternal antibodies directed against fetal red blood cell (RBC) antigens and can lead to severe morbidity and mortality. Anti-M is usually a naturally occurring antibody of low clinical significance, although occasionally severe cases of HDFN are seen.

CASE REPORTS: Two $M+$ sisters are presented, each developing hemolysis during the first 2 weeks of life due to maternal anti-M, resulting in severe anemia and requiring blood transfusion. RBC agglutination was observed in peripheral blood samples of both infants at room temperature with dissociation at $37^{\circ} \mathrm{C}$. Maternal anti-M detected by column indirect agglutination technique, was of low titer (1:16) and demonstrated low thermal amplitude, reacting in saline at $4^{\circ} \mathrm{C}$ but was not detectable in saline at $37^{\circ} \mathrm{C}$.

CONCLUSIONS: Anti-M of low thermal amplitude may cause hemolytic disease of the newborn with laboratory features resembling cold agglutinin disease.

\section{CASE PRESENTATION}

1 20-day-old female infant presented to the emergency department in 2014 with vomiting, diarrhea, and failure to thrive. Her hemoglobin (Hb) was measured at $41 \mathrm{~g} / \mathrm{L}$ and red blood cell (RBC) agglutination was noted in the whole blood sample and on the peripheral blood smear at room temperature (RT), dissociating at $37^{\circ} \mathrm{C}$. The direct antiglobulin test (DAT) was negative, bilirubin was $55 \mu \mathrm{mol} / \mathrm{L}(3.22 \mathrm{mg} / \mathrm{dL}$, normal $<14 \mu \mathrm{mol} / \mathrm{L}$ ) and haptoglobin could not be detected. The infant was transfused to an $\mathrm{Hb}$ of $109 \mathrm{~g} / \mathrm{L}$, her feeding improved, and she was discharged home.

At Day 16 after transfusion, a scheduled repeat blood count showed an $\mathrm{Hb}$ of $54 \mathrm{~g} / \mathrm{L}$. The bilirubin had fallen to $34 \mathrm{~g} / \mathrm{L}(1.99 \mathrm{mg} / \mathrm{dL})$, but haptoglobin remained absent and RT RBC agglutination persisted. Tiredness, falling asleep during feeds, and pallor were noted by her parents. The child was transferred to a quaternary pediatric center following a second transfusion. Paroxysmal cold hemoglobinuria (PCH) was considered following the finding of a single erythrophagocytic monocyte. Intravenous immunoglobulin was administered. No further transfusions were required,

ABBREVIATIONS: DAT = direct antiglobulin test; DL = DonathLandsteiner; HDFN = hemolytic disease of the fetus and newborn; IAT = indirect antiglobulin test; $\mathrm{PCH}=$ paroxysmal cold hemoglobinuria; RT = room temperature.

From the ${ }^{1}$ Haematology Department, ACT Pathology, the ${ }^{2}$ Clinical Haematology, Canberra Hospital, the ${ }^{4}$ Maternofetal Medicine Unit, Centenary Hospital for Women and Children, Garran, ACT Australia; and the ${ }^{3}$ Medical School, Australian National University, Acton ACT Australia.

Address reprint requests to: Philip Crispin, Clinical 
and follow-up peripheral blood smear showed no agglutination at 3 months of age with a normal $\mathrm{Hb}(118 \mathrm{~g} / \mathrm{L})$.

The maternal history included treated hypothyroidism. Her blood group was B D negative, extended phenotype: C-E$\mathrm{c}+\mathrm{e}+, \mathrm{K}-\mathrm{k}+, \mathrm{Fy}(\mathrm{a}+\mathrm{b}-), \mathrm{Jk}(\mathrm{a}+\mathrm{b}-), \mathrm{M}-\mathrm{N}+, \mathrm{S}-\mathrm{s}+$, and anti-M was found during this, her first pregnancy, with a titer of 2 at delivery (by another laboratory). Prophylactic anti-D had been administered at 28 and 34 weeks as per local practice guidelines. The pregnancy was otherwise uncomplicated. Upon referral to our hospital, maternal investigations confirmed the presence of a low-titer anti-M and a low-titer anti-D (consistent with prophylactic administration), by column indirect antiglobulin test (IAT). The plasma also demonstrated low thermal reactivity of the anti-M using single-dose $\mathrm{M}+, \mathrm{D}-\mathrm{RBC}$ at $4^{\circ} \mathrm{C}$ in saline. RBC agglutination was not observed on the maternal peripheral blood smear. Maternal investigations included normal bilirubin, absolute reticulocyte count and DAT, negative Donath-Landsteiner (DL) test, glucose-6-phosphate dehydrogenase deficiency screen, and normal $\mathrm{Hb}$ electrophoresis. Serology for cytomegalovirus, parvovirus, and Epstein-Barr virus were each positive for immunoglobulin G (IgG) but not immunoglobulin M (IgM), consistent with prior infection. The father was B D positive, $\mathrm{M}+$, and $\mathrm{N}$ - and also had a negative glucose-6-phosphate dehydrogenase deficiency screen and normal $\mathrm{Hb}$ electrophoresis.
In 2017 the mother presented for management of her second pregnancy. The anti-M remained detectable in her plasma, and anti-D prophylaxis was administered at 28 and 34 weeks' gestation. The anti-M was monitored throughout the pregnancy by titers performed by column IAT with use of double-dose $\mathrm{M}+$, D- RBCs and by direct agglutinating saline tube method with single-dose $\mathrm{M}+, \mathrm{D}-\mathrm{RBCs}$ at $4^{\circ} \mathrm{C}$, $\mathrm{RT}, 30^{\circ} \mathrm{C}$, and $37^{\circ} \mathrm{C}$. The results are shown in Table 1 , demonstrating no significant increase in the anti-M titer during pregnancy, but showing the antibody to have a low thermal amplitude in saline. Although testing at 26 weeks resembled anti-i, this was not identified on prior or subsequent testing. Monitoring of the fetus by ultrasound showed growth remained within expected limits for fetal age and serial fetal middle cerebral artery Doppler ultrasound to screen for fetal anemia also remained normal throughout the pregnancy.

A female neonate was delivered by cesarean section at 39 weeks. The neonate was typed as $\mathrm{O} D$ positive, $\mathrm{M}+\mathrm{N}+$. Cord blood demonstrated marked macroscopic RBC agglutination in the collection tube at RT, a positive DAT (grade 2/4) with anti-M and anti-D (consistent with prophylactic anti-D administration) eluted from the cord blood cells. At 6 hours, her $\mathrm{Hb}$ was $167 \mathrm{~g} / \mathrm{L}$ with severe RT RBC agglutination noted on the peripheral blood smear, dissociating on warming to $37^{\circ} \mathrm{C}$ (Fig. 1). The child was kept in a heated

\begin{tabular}{|c|c|c|c|c|c|c|c|c|c|}
\hline \multirow[b]{2}{*}{ Gestation } & \multirow{2}{*}{$\begin{array}{c}37^{\circ} \mathrm{C} \text { IAT } \\
\mathrm{M}+\mathrm{N}-, \mathrm{D}- \\
\text { Adult }\end{array}$} & \multicolumn{2}{|c|}{$37^{\circ} \mathrm{C}$ saline $\mathrm{M}+\mathrm{N}+, \mathrm{D}-$} & \multicolumn{2}{|c|}{$30^{\circ} \mathrm{C}$ saline $\mathrm{M}+\mathrm{N}+, \mathrm{D}-$} & \multicolumn{2}{|c|}{ RT saline $\mathrm{M}+\mathrm{N}+$, D- } & \multicolumn{2}{|c|}{$4^{\circ} \mathrm{C}$ saline $\mathrm{M}+\mathrm{N}+, \mathrm{D}-$} \\
\hline & & Adult & Cord & Adult & Cord & Adult & Cord & Adult & Cord \\
\hline 26 weeks & 8 & $<2$ & 8 & $<2$ & 64 & $<2$ & 128 & 32 & 256 \\
\hline 30 weeks & 8 & NP & NP & NP & NP & NP & NP & NP & NP \\
\hline 32 weeks & 8 & $<2$ & $<2$ & $<2$ & $<2$ & $<2$ & $<2$ & $<2$ & $<2$ \\
\hline 35 weeks & 16 & $<2$ & $<2$ & $<2$ & $<2$ & 8 & 16 & 32 & 32 \\
\hline Delivery & NP & $<2$ & $<2$ & $<2$ & 16 & 16 & 32 & 32 & 32 \\
\hline $\begin{array}{c}1 \text { week after } \\
\text { delivery }\end{array}$ & NP & $<2$ & 16 & $<2$ & 16 & 2 & 16 & 256 & 64 \\
\hline
\end{tabular}
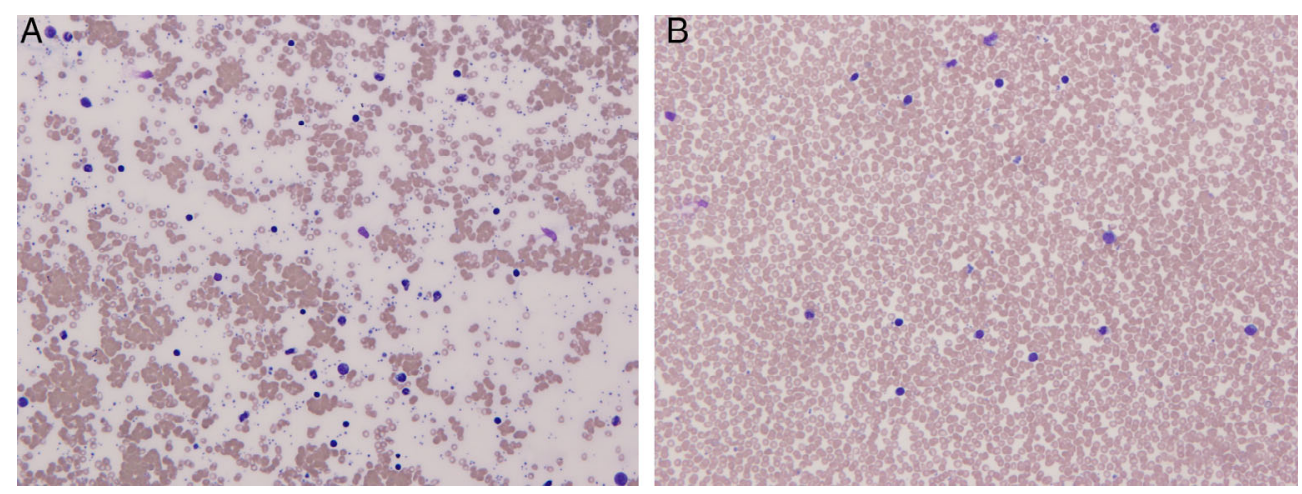

Fig. 1. RBC agglutination in the second infant at room temperature (A), dissociating at $37^{\circ} \mathrm{C}(\mathrm{B})$. 


\section{BABY 2: HB AND BILIRIBIN OVER TIME}

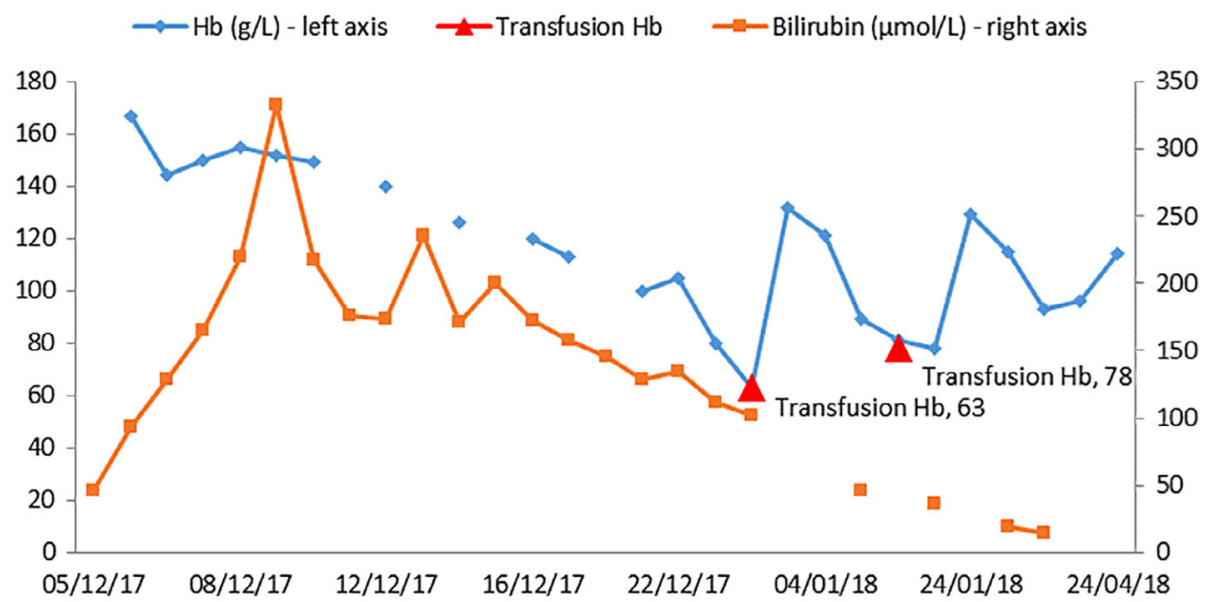

Fig. 2. Time course of anemia and bilirubin in the second infant. [Color figure can be viewed at wileyonlinelibrary.com]

crib during hospitalization. Hyperbilirubinemia developed and phototherapy was instituted. The $\mathrm{Hb}$ fell over the first week, with significant anemia ( $\mathrm{Hb}$ of $63 \mathrm{~g} / \mathrm{L}$ ) developing after discharge. Readmission for transfusion was required on two occasions, but by 4 months of age the $\mathrm{Hb}$ normalized, independent of transfusion. The time course of the bilirubin and $\mathrm{Hb}$ are shown in Fig. 2.

\section{DISCUSSION}

The $\mathrm{M}$ and $\mathrm{N}$ antigens are antithetical RBC antigens attributed to the structural RBC protein glycophorin A. Anti-M is one of the most common antibodies detected, accounting for more than one-half of the alloantibodies seen in a recent healthy donor population. ${ }^{1}$ Frequently detected as coldreacting, naturally occurring (without prior RBC exposure) antibodies, anti-M predominantly occurs as an IgM class antibody; however, a majority contain a component of IgG. $^{2,3}$ As such, anti-M typically agglutinates RBCs in saline and has stronger reactivity at lower temperatures, properties usually attributed to IgM class antibodies. When not reacting at $37^{\circ} \mathrm{C}$, anti-M is considered to be of no clinical significance.

In pregnancy, anti-M accounts for around $10 \%$ to $19 \%$ of antibodies ${ }^{4,5}$ and does not appear to be associated with the risk of developing additional antibodies during pregnancy. ${ }^{6}$ Large series have shown that anti-M is usually not associated with adverse effects in pregnancy, despite the antigens being well developed at birth. ${ }^{5-8}$ However, there are sporadic case reports in the literature of both hemolytic transfusion reactions and severe hemolytic disease of the fetus and newborn (HDFN) associated with anti-M. ${ }^{9-11}$ The severity of HDFN ranging from requiring transfusion or immunoglobulin therapy to fatal fetal hydrops, and has been recently reviewed. ${ }^{7,11-14}$
Cold agglutinins are predominantly IgM class antibodies and are typically seen in association with infection, such as mycoplasma or Epstein-Barr virus, with lymphoproliferative disorders or may be idiopathic. Occasionally, cold-reacting antibodies are IgG, with the DL antibody being typical, although detection of this antibody may be missed by standard antiglobulin tests, and it does not usually cause cold agglutination. It results in the clinical syndrome of $\mathrm{PCH}$, which may be seen with infection, such as transient viral infections in childhood or syphilis in adults.

The present case describes an antibody associated with RT RBC agglutination, which has not previously been described in HDFN. The maternal antibody caused no harm or RBC agglutination in the mother, as expected from an alloantibody. It was detected in the serum of both her $\mathrm{M}_{+}$ children in association with delayed-onset severe anemia and RBC agglutination on the peripheral blood smear, which dissociated on warming. It was not associated with hemolysis at the time of birth, presumably due to the warm environment. Despite the severe consequences from this antibody, serologically it had many characteristics usually associated with clinically insignificant anti-M: there was no prior known RBC antigen exposure, consistent with a naturally occurring anti-M; it was of low titer, with 1:16 being the highest titer during the second pregnancy; and it had a low thermal amplitude, being unreactive at $37^{\circ} \mathrm{C}$ in saline. However, it was detectable by IAT at $37^{\circ} \mathrm{C}$. Possible explanations for this constellation of findings include:

1. Maternal IgG anti-M crossing the placenta causing hemolysis and cold agglutination. Direct agglutination of RBCs with IgG class anti-M in saline has been attributed to the high frequency of the antigen on the RBC surface and the distal site of the epitope on the glycophorin A antigen. ${ }^{2}$ Whether hemolysis predominated at $37^{\circ} \mathrm{C}$ or in the cold is uncertain in this case, although the 
development of anemia only after delivery suggests the low in vitro thermal amplitude may be relevant in vivo.

2. Maternal anti-M, including IgM antibodies, crossing the placenta to account for the significant RBC agglutination. $\mathrm{RBC}$ agglutination is more typically seen with $\operatorname{IgM}$, as its large structure enables it to bridge between charged RBC surfaces, although this same property limits placental passage.

3. Hemolysis could be explained by an undetected antibody to a low-incidence paternal antigen present on infant RBCs. As these are usually IgG and require prior antigen exposure, hemolysis after the first pregnancy and RT agglutination seen in the infants' samples would be unlikely. Ideally, an IAT with maternal plasma and paternal RBCs, following alloabsorption of anti-M would exclude this possibility.

Typically, cold or saline reactivity is associated with IgM antibodies, whereas IgG antibodies require IAT. Also, IgM antibodies do not typically cross the placenta. This case requires that we challenge one or both of these assumptions. Without having separated maternal isotypes, we cannot attribute it specifically to either. Nevertheless, the finding of maternally derived RBC cold agglutination, whether from IgG antibodies or from IgM antibodies, is an important novel clinical finding. This report should alert clinicians to the rare potential for fetomaternal transmission of cold-acting antibodies.

The characteristics of anti-M-mediated HDFN have not been well described due to its rarity. Yasuda et al. ${ }^{11}$ collated all 33 reported Japanese cases, finding an association with reticulocytopenia and the severity of anemia. This likely represents antibody binding to $\mathrm{M}+$ erythroblasts reducing erythropoiesis and has been described by others. ${ }^{15}$ Yasuda et al. also found that one-third of cases occurred with low titer anti-M. As in this case, the infant in their index case also had a negative DAT. Their series also included infants with delayed-onset anemia, and it is unknown whether a lower thermal amplitude was a contributing factor.

The rarity of anti-M-mediated HDFN poses a problem for obstetricians and transfusion laboratories alike. Monitoring during pregnancy with serial titers or ultrasound is likely to be of very low yield, as the majority of cases will not be associated with adverse events and the titers potentially misleading. Stetson et al. $^{7}$ have provided recommendations for screening that include correlation with a prior history of HDFN and serial titers. Although these recommendations are less onerous than for clinically significant antibodies, it is noted that no cases of anti-M-associated HDFN have been seen at their center for 50 years, and their algorithm remains untested. ${ }^{7,8}$ Furthermore, our first pregnancy case would have escaped additional attention with the proposed regimen. ${ }^{11}$ Awareness of unusual or severe outcomes with anti-M should therefore be maintained, despite a low absolute risk. The cases do, however, have implications for management. In particular, if RBC agglutination is present on a neonatal peripheral blood smear, examination of the maternal blood for cold-acting antibodies directed against the neonatal or paternal RBCs should be considered, and closer observation for delayed anemia is appropriate.

A differential diagnosis of $\mathrm{PCH}$ was offered, but we felt that this was unlikely. To our knowledge, the DL antibody has not been described in neonates and seems very unlikely due to the rarity of $\mathrm{RBC}$ antibody development in this age group. ${ }^{16}$ The presence of RBC agglutination in both infants and the negative maternal DL test also weigh against this diagnosis. Ideally, confirmation of the IgG antibody, such as with dithiothreitol treatment, should be undertaken; however, licensed dithiothreitol was not available at the time of the serologic investigations. The lack of this confirmation does not hinder the main conclusion of anti-M alloantibody causing HDFN and cold agglutination.

\section{CONCLUSIONS}

This case describes severe HDFN requiring transfusion in two sisters, with laboratory features resembling cold agglutinin disease due to a passively transferred maternal anti-M. Coldacting antibodies should be considered when there is suspicion of HDFN and a negative DAT or when RBC agglutination is observed on the peripheral blood smear of a neonate.

\section{CONFLICT OF INTEREST}

The authors have disclosed no conflicts of interest.

\section{REFERENCES}

1. Makroo RN, Rajput S, Agarwal S, et al. Prevalence of irregular red cell antibody in healthy blood donors attending a tertiary care hospital in North India. Asian J Transfus Sci 2018;12: 17-20.

2. Smith ML, Beck ML. The immunoglobulin structure of human anti-M agglutinins. Transfusion 1979;19:472-4.

3. Makroo RN, Arora B, Bhatia A, et al. Clinical significance of antibody specificities to $\mathrm{M}, \mathrm{N}$ and Lewis blood group system. Asian J Transfus Sci 2014;8:96-9.

4. Smith HM, Shirey RS, Thoman SK, et al. Prevalence of clinically significant red blood cell alloantibodies in pregnant women at a large tertiary-care facility. Immunohematology 2013;29:127-30.

5. Bollason G, Hjartardottir H, Jonsson T, et al. Red blood cell alloimmunization in pregnancy during the years 1996-2015 in Iceland: a nation-wide population study. Transfusion 2017;57: 2578-85.

6. Koelewijn JM, Vrijkotte TGM, Van Der Schoot CE, et al. Effect of screening for red cell antibodies, other than anti-D, to detect hemolytic disease of the fetus and newborn: a population study in the Netherlands. Transfusion 2008;48:941-52. 
7. Stetson B, Scrape S, Markham KB. Anti-M alloimmunization: management and outcome at a single institution. AJP Rep 2017;7:e205-e10.

8. De Young-Owens A, Kennedy M, Rose RL, et al. Anti-M isoimmunization: management and outcome at the Ohio State University from 1969 to 1995. Obstet Gynecol 1997;90:962-6.

9. Parry-Jones N, Gore ME, Taylor J, et al. Delayed haemolytic transfusion reaction caused by anti-M antibody in a patient receiving interleukin-2 and interferon for metastatic renal cell cancer. Clin Lab Haematol 1999;21:407-8.

10. Sancho JM, Pujol M, Fernandez F, et al. Delayed haemolytic transfusion reaction due to anti-M antibody. Br J Haematol 1998;103:268-9.

11. Yasuda H, Ohto H, Nollet KE, et al. Hemolytic disease of the fetus and newborn with late-onset anemia due to anti-M: a case report and review of the Japanese literature. Transfus Med Rev 2014;28:1-6.
12. Wikman A, Edner A, Gryfelt G, et al. Fetal hemolytic anemia and intrauterine death caused by anti-M immunization. Transfusion 2007;47:911-7.

13. Bowley CC, Dunsford I. The agglutinin anti-M associated with pregnancy; report on two cases. Br Med J 1949; 2:681-2.

14. Hubinont C, Delens G, Vanalbada De Haan Hettema J, et al. Successful management of a severe anti-M alloimmunization during pregnancy. Eur J Obstet Gynecol Reprod Biol 2017; 217:175-6.

15. Ishida A, Ohto H, Yasuda $H$, et al. Anti-M antibody induced prolonged anemia following hemolytic disease of the newborn due to erythropoietic suppression in 2 siblings. J Pediatr Hematol Oncol 2015;37:e375-7.

16. Turkmen T, Qiu D, Cooper N, et al. Red blood cell alloimmunization in neonates and children up to 3 years of age. Transfusion 2017;57:2720-6. 